\title{
Hospital Care for Opioid use in Illinois, 2016-2019
}

\author{
Joe Feinglass, PhD \\ Jessica Ann Wang, MD, MPH \\ Jiancheng Ye, MS \\ Robert Tessier, BS \\ Howard Kim, MD, MS
}

\begin{abstract}
This study analyzes trends in hospital emergency room visits and admissions for patients with opioid diagnoses seen at 214 hospitals in Illinois over 42 months. Visits were coded hierarchically for opioid overdose, dependence, abuse, or use. Visit rates per 100,000 were stratified by zip code level of poverty. Regression estimates of the likelihood of inpatient admission and death are presented. There were 239,069 visits accounting for almost $\$ 5$ billion in total charges and over 710,000 inpatient hospital days with less than a 1\% death rate. The Illinois opioid epidemic is concentrated in the poorest areas of the Chicago metropolitan area. There was a sharp gradient in visits rates and deaths rates by poverty level area and more than a fivefold difference in hospital deaths. Effective state policy responses should expand to include decriminalization and proven harm reduction strategies such as medically assisted treatment, access to safe syringes, take home naloxone, and supervised safe consumption facilities.
\end{abstract}

According to the Illinois Department of Public Health (IDPH), despite an approximately 10\% decrease in opioid prescriptions, opioid deaths more than doubled between 2013 and 2017, fueled by a tenfold increase in deaths due to synthetic opioids. There was a small $1.6 \%$ decline in overdose deaths in 2017-2018, from 2202 to 2167. However, hospital emergency department (ED) overdose visits increased throughout the 2013-2018 period. Emergency medical services (EMS)

Address correspondence to Joe Feinglass, PhD, Division of General Internal Medicine and Geriatrics, Northwestern University Feinberg School of Medicine, General Internal Medicine and Geriatrics, 750 Lakeshore Drive 10th Floor, Chicago, IL 60611312 503-6443, USA. Email: j-feinglass@ northwestern.edu.

Jessica Ann Wang, MD, MPH, Northwestern University Masters In Public Health Degree Program, Chicago, IL, USA. Robert Tessier, BS, Northwestern University Masters In Public Health Degree Program, Chicago, IL, USA.

Jiancheng Ye, MS, Health Sciences Integrated PhD Program, Northwestern University Feinberg School of Medicine, Chicago, IL, USA.

Howard Kim, MD, MS, Northwestern University Feinberg School of Medicine, Chicago, IL, USA.

Journal of Behavioral Health Services \& Research, 2021. 597-609. (C) 2021 National Council for Behavioral Health. DOI 10.1007/s11414-020-09748-8 
administrations of naloxone, including encounters with multiple administrations, also increased through 2018. ${ }^{1}$ Beginning even before the COVID-19 epidemic provisional estimates indicated an alarming new spike in opioid-related overdose deaths in $2020 .^{2}$

While the IDPH reports have focused on overdose treatment and deaths, there has been limited data on the overall impact of opioid use on the hospital system, which extends to encounters beyond those for overdose. According to the Statewide Unintentional Drug Overdose Reporting System (SUDORS) of the Centers for Disease Control and Prevention's (CDC) Enhanced State Opioid Overdose Surveillance (ESOOS) program, almost $80 \%$ of Illinois overdose deaths occur in the community rather than a hospital. ${ }^{3}$ Many of those who died in the community had a (sometimes long) history of prior hospital care for opioid use. As one recent study of emergency department visits linked to subsequent opioid-related deaths has shown, examining patterns of hospital use may be critical in identifying those at highest risk of death. ${ }^{4}$ Hospitals can play a pivotal role in addressing what remains a substantial gap in treatment after non-fatal overdose events. ${ }^{5}$

This analysis was undertaken to provide a fuller picture of the burden of the opioid epidemic on Illinois hospitals. The study provides data on all ED visits and inpatient admissions related to opioid use, abuse, dependence, and overdose and models the association of patient sociodemographic characteristics with the likelihood of hospital admission and death over 42 months from 2016 to 2018. It also uses census data for Illinois zip code tabulation areas to compute opioid hospital visit rates per 100,000 by percentage of poverty level households.

\section{Methods}

Administrative data from 214 non-federal Illinois hospitals were obtained from the Illinois Hospital Association Comparative Health Care and Hospital Data Reporting Services for all ED or inpatient encounters with ICD-10 opioid codes from January 2016 to June 2019. These included Center for Disease Control Opioid Overdose Indicator Support Toolkit version $3.0^{6}$ as well as other ICD-10 T40 codes and F11 codes corresponding to opioid use. Visits were characterized hierarchically by ICD-10 coding as being for use, abuse, dependence, or overdose. Opioid type codes (heroin, methadone, or synthetic opioid) are not included as hospital coding for these are not reliable; synthetic opioid codes were only documented for $1 \%$ of overdose visits, and toxicology data may not have been readily available. Patient data included patient sex, age $(<20,20-44,45-$ 64 , and $>65$ ), race and ethnicity (non-Hispanic black, non-Hispanic white, Hispanic, Asian, other/ unknown), insurance status (private, Medicare age 65 and Medicare disability, Medicaid, uninsured or other/unknown), Illinois county area (Cook, suburban Chicago DuPage, Kane, Will, Lake or McHenry, or any other 'downstate' county), day of visit (weekday vs. weekend), and if the patient died in the hospital. Visits were characterized as ED discharge or inpatient stays via direct or ED admission. Patient zip codes were matched to the 2017 American Community Survey 5-year census data for the proportion of Illinois zip code tabulation area (ZCTA) residents living at or below the federal poverty level, grouped as $<5 \%, 5-9.99 \%, 10-19.99 \%$, and $>20 \%$ and for the $3 \%$ of all encounters with non-Illinois residents. The three areas with $<20 \%$ poor households each accounted for just under $30 \%$ of the Illinois population with the highest poverty area having about $12 \%$ of the state's population. County level urbanicity was measured as rural or small urban $(<$ 250,000 population) versus larger metro areas using the US Department of Agriculture 2013 rural urban continuum codes. This study is exempt from IRB approval as it is restricted to publicly available, de-identified data, and there are no author conflicts of interest.

\section{Statistical Analysis}

Chi-square tests were used to determine the statistical significance of differences in opioid encounters by patient characteristics. Annual average opioid hospital visit rates per 100,000 were 
calculated for each of the four poverty-level ZCTA areas. Monthly trends in the number of opioid visits were calculated by code type and by poverty level area. Poisson regression models of the likelihood of hospital admission and the likelihood of hospital death to were estimated to obtain incident rate ratios (IRR), respectively, for patient characteristics. Standard errors were adjusted for clustering of observations within hospitals. All analyses were conducted using STATA/SE version 15, College Station, Texas.

\section{Results}

There were 231,977 opioid-related hospital visits for Illinois residents over the 42-month study period, including 46,546 (19.5\%) coded as overdoses and about half $(115,767)$ coded as opioid dependence (Table 1). About $46 \%$ of all visits were discharged ED visits; $31 \%$ were inpatient admissions through the ED, and $24 \%$ were direct inpatient admissions. Over $60 \%$ of visits were for men and $91.3 \%$ were for people between the ages of 20 and 64. Cook County, with about $40 \%$ of the state's population, accounted for $60 \%$ of all opioid hospital visits; rural small urban counties accounted for only about $11 \%$ of visits. Given that the Illinois population is approximately $70 \%$ non-Hispanic white, there was an evident racial disparity as only $45.5 \%$ of visits were for nonHispanic whites (although they accounted for over $50 \%$ of all overdose coded visits). While nonHispanic blacks were less than $14 \%$ of the Illinois population, they accounted for over $37 \%$ of all visits and almost $32 \%$ of overdose coded visits. Conversely, Hispanics were over $17 \%$ of the Illinois population but accounted for less than $8 \%$ of visits. Half of all visits were covered by Medicaid and less than $9 \%$ were uninsured. Only a little over $1 \%$ of all overdose visits resulted in a hospital death. Figure 1 displays monthly time trends over the study period for each type of visit, indicating a modest decrease in dependence-coded visits and a slight increase in overdose-coded visits.

\section{Opioid Visit and Hospital Death Rates by Poverty Level Areas}

Table 2 displays opioid visit and hospital death rates per 100,000 population. The statewide visit rate was 531 per 100,000 and the hospital death rate was 3.45 per 100,000 . There was a sharp socioeconomic gradient in both visits and death rates across areas. To fully appreciate the magnitude these differences, the all-ages rate was more than six times higher in the highest poverty areas, with 1636 per 100,000, than in the most affluent area with 258 per 100,000. Similarly, the all-ages hospital death rate increased more than fivefold from the lowest poverty level area (1.79 per 100,00$)$ to the highest poverty level area $(10.49$ per 100,000). Both visit and death rates were generally much higher for the age 45-64 population. Figure 2 shows how the rates of overdose visits changed over time across poverty areas. While all areas peaked in 2018 , areas with $10 \%$ or more ZCTA saw increases in overdose rates over the remaining months.

\section{Regression Results for the Likelihood of Inpatient Admission and Death}

Table 3 presents IRRs for the likelihood of hospital death or inpatient admission. For hospital death, a rare event affecting less than $1 \%$ of visits, the only prominent risk factors were older age, an overdose diagnosis, and being a weekend ED visit or admission; non-Hispanic black patients were $22 \%$ less likely to die during a hospital visit. Hospital admissions, affecting over half of all visits, were significantly less likely after 2016, for men, for patients age 20-44, and for weekend visits. Those with Medicaid (IRR $=0.92)$ or without insurance $(I R R=0.51)$ were both significantly less likely to be hospitalized than those with private insurance. 


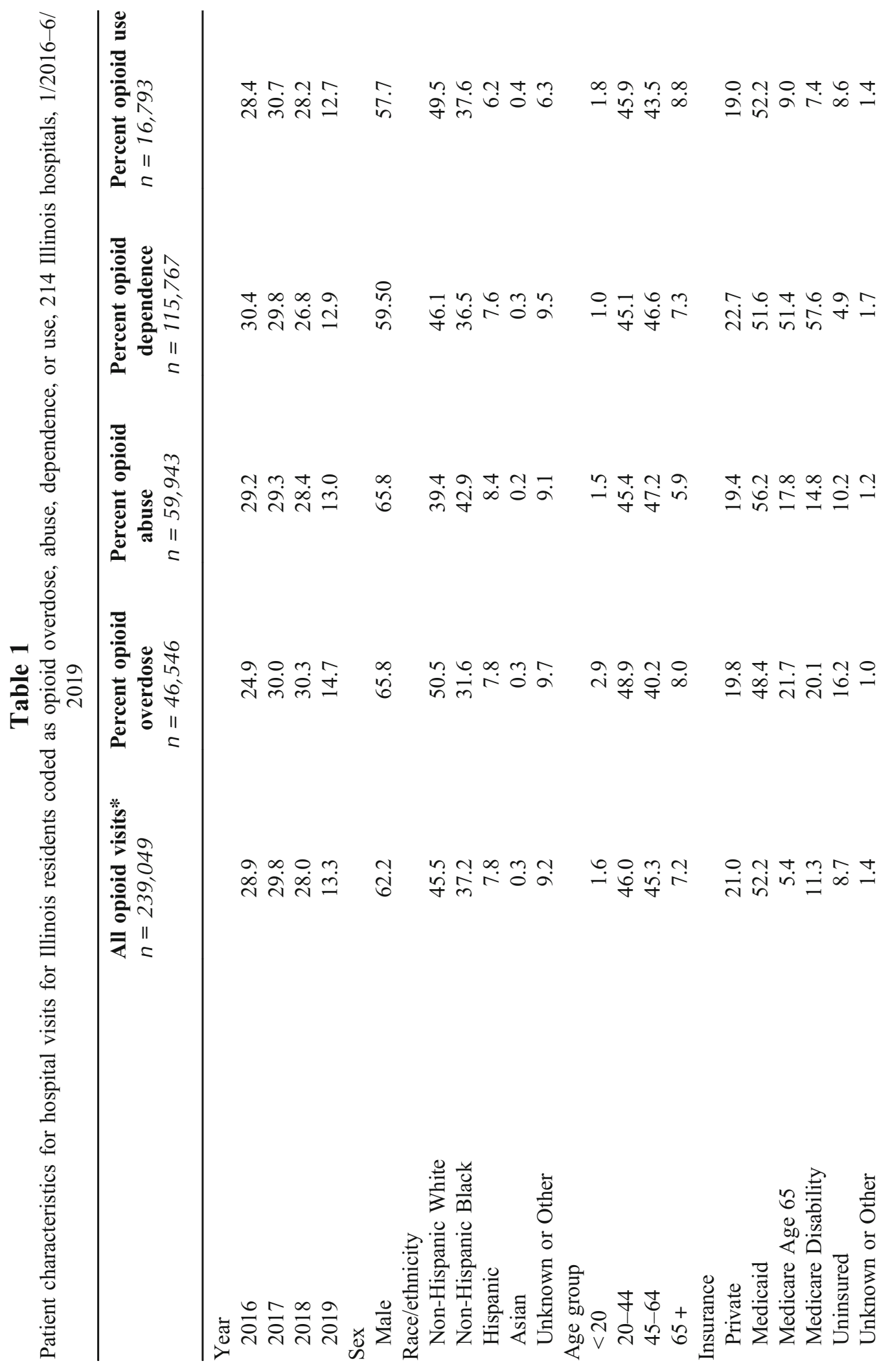




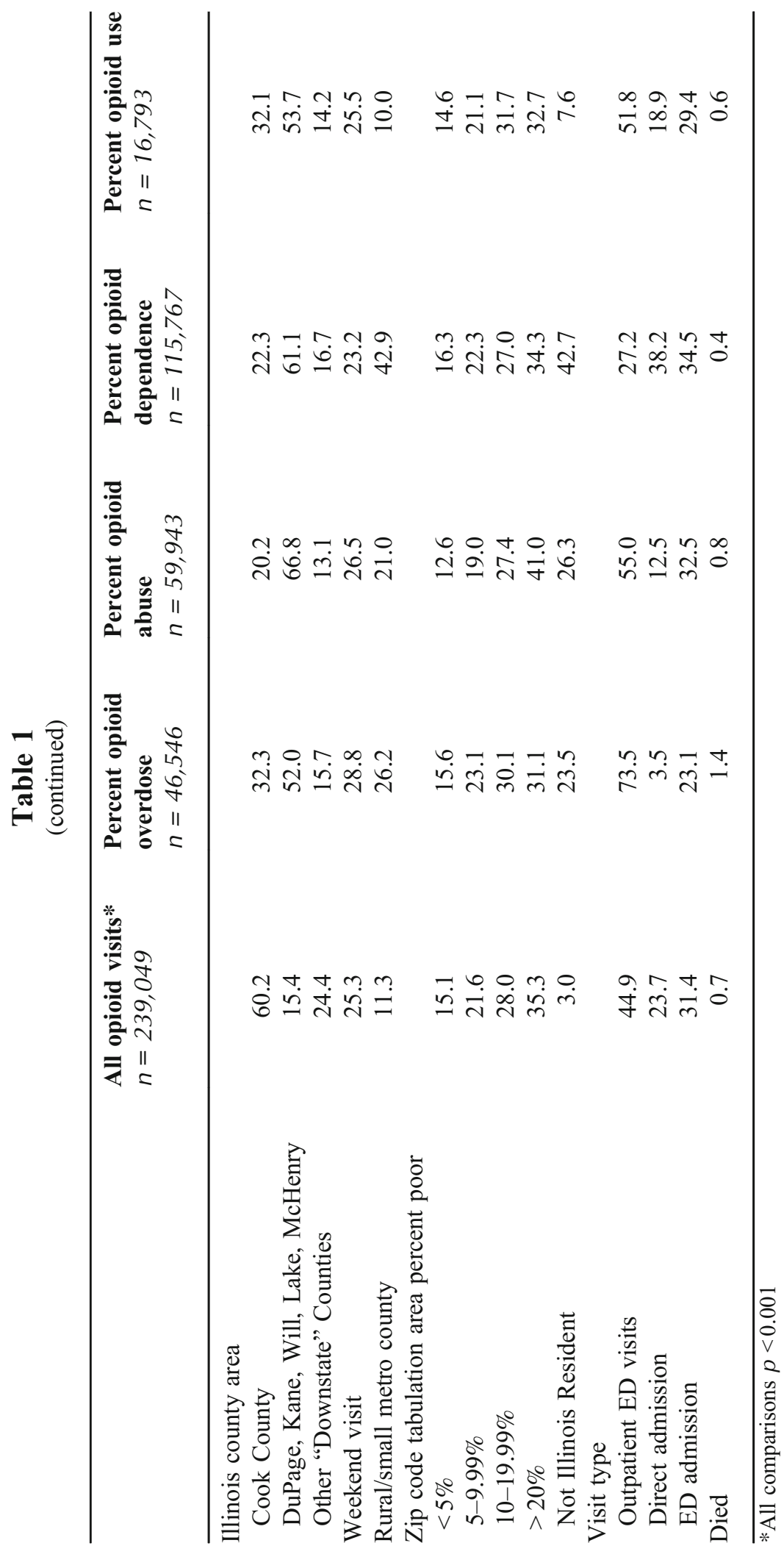




\section{Figure 1}

Monthly trends in hospital visits for opioid use, 214 Illinois hospitals, 1/2016-6/2019

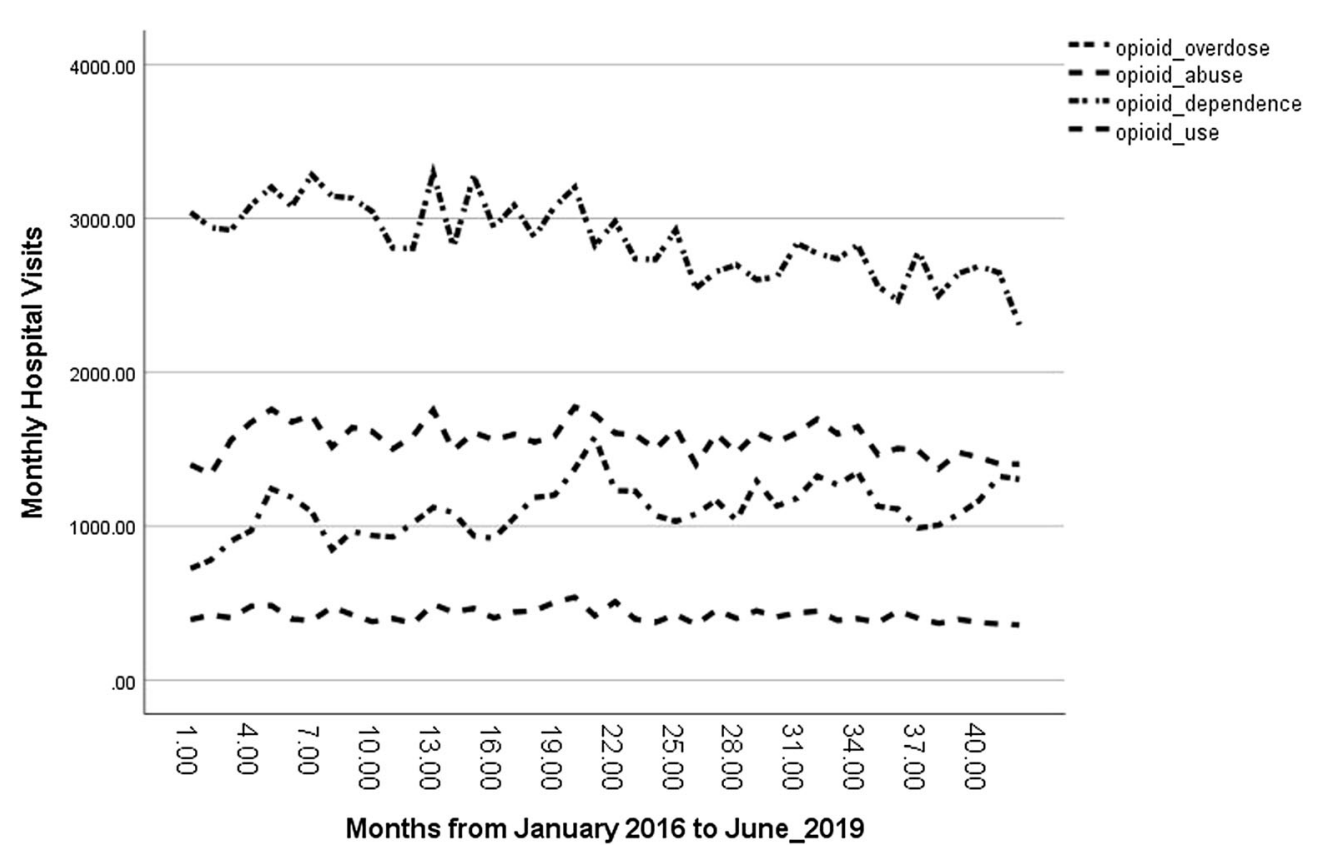

\section{Behavioral Health Implications}

While the opioid epidemic death rate has drawn a great deal of attention, the huge additional burden of opioid-related hospital care has not been as well publicized. The 239,049 ED and inpatient encounters in Illinois over the three years in this study had $\$ 4,937,273,015$ in total charges and the admissions resulted in 710,884 inpatient hospital days. Over three quarters of these costs were born by public insurance. Reflecting frequent comorbidity, less than $20 \%$ of these visits were coded as opioid overdose. These Illinois data are consistent with national trends showing that the epidemic had a modest downturn in 2018-2019, but given the spike in deaths during the COVID-19 pandemic, there is no evidence that the decrease in opioid-related overdose deaths was sustained.

\section{The Illinois Drug Use Environment}

The 1615 hospital deaths analyzed in this study reflect just over $20 \%$ of all opioid overdose deaths in Illinois during the study period. ${ }^{1}$ Only $16 \%$ of Illinois overdose deaths in 2016 were related to prescription opioids. ${ }^{7}$ Analyses of Cook County opioid overdose deaths provide additional insight into the epidemiology of the epidemic in Illinois. Opioid deaths in Cook County are driven by fentanyl-related overdoses, as fentanyl is both more lethal and is less expensive per dose than heroin. That study demonstrated a bifurcated drug market in Cook County, with fatal fentanyl overdoses concentrated in high deprivation areas with high indices of racial segregation, with opioid analgesic, heroin, and polydrug overdose deaths more common in outlying, more affluent areas of the county. ${ }^{8}$ The Cook County study mirrors the findings here about the 


\section{Table 2}

Average annual rates per 100,000 for Illinois Residents for Outpatient Emergency Department (ED) visit or inpatient admission and hospital death for patients with an opioid diagnosis, by Zip code tabulation area (ZCTA) percent of households living in poverty 214 Illinois Hospitals, $1 / 2016-6 / 2019$.

\begin{tabular}{|c|c|c|c|}
\hline & $\begin{array}{l}\text { Total Illinois } \\
\text { population estimate* }\end{array}$ & $\begin{array}{l}\text { Opioid visit } \\
\text { rate per } 100,000\end{array}$ & $\begin{array}{l}\text { Hospital death } \\
\text { rate per } 100,000\end{array}$ \\
\hline \multicolumn{4}{|c|}{$<5 \%$ of ZCTA poor households } \\
\hline Age 0-19 & 978,737 & 31.70 & 0.02 \\
\hline Age $20-44$ & $1,216,881$ & 508.65 & 2.79 \\
\hline Age $45-64$ & $1,100,737$ & 254.19 & 1.89 \\
\hline Age $65+$ & 582,617 & 127.42 & 2.45 \\
\hline Total & $3,878,972$ & 258.84 & 1.79 \\
\hline \multicolumn{4}{|c|}{$5-9.99 \%$ of ZCTA poor households } \\
\hline Age 0-19 & 937,560 & 31.90 & 0.12 \\
\hline Age $20-44$ & $1,253,194$ & 687.59 & 3.39 \\
\hline Age 45-64 & $1,016,623$ & 436.51 & 3.87 \\
\hline Age $65+$ & 570,408 & 163.94 & 2.75 \\
\hline Total & $3,777,785$ & 378.23 & 2.62 \\
\hline \multicolumn{4}{|c|}{$10-19.99 \%$ of ZCTA poor households } \\
\hline Age 0-19 & 976,811 & 28.84 & 0.15 \\
\hline Age $20-44$ & $1,358,892$ & 681.56 & 3.68 \\
\hline Age 45-64 & 919,939 & 850.55 & 6.21 \\
\hline Age $65+$ & 515,603 & 235.85 & 3.43 \\
\hline Total & $3,771,245$ & 492.78 & 3.49 \\
\hline \multicolumn{4}{|c|}{$>20 \%$ of ZCTA poor households } \\
\hline Age 0-19 & 409,684 & 28.43 & 0.14 \\
\hline Age $20-44$ & 503,349 & 1207.96 & 4.65 \\
\hline Age 45-64 & 337,531 & 4517.42 & 30.05 \\
\hline Age $65+$ & 179,529 & 1070.42 & 13.52 \\
\hline Total & $1,427,393$ & 1636.93 & 10.49 \\
\hline \multicolumn{4}{|c|}{ All Illinois population } \\
\hline Age 0-19 & $3,302,792$ & 31.99 & 0.10 \\
\hline Age $20-44$ & $4,332,316$ & 724.73 & 4.03 \\
\hline Age 45-64 & $3,374,830$ & 916.88 & 6.47 \\
\hline Age $65+$ & $1,848,157$ & 265.23 & 3.89 \\
\hline Total & $12,855,395$ & 531.29 & 3.45 \\
\hline
\end{tabular}

- Based on population estimates from 2017 American Community Survey 5 Year Census Data.

concentration of opioid hospital use in the same high poverty neighborhoods where fentanyl has become increasingly common. The hospital data analyzed here indicates that hospital use for the opioid epidemic in Illinois is primarily based in lower-income areas of the Chicago metropolitan area, among populations with the least access to high-quality treatment programs. Although there were no significant race and ethnicity differences in hospital admissions or hospital deaths, there was a vastly disproportionate number of overall hospital visits by Cook County, non-Hispanic black residents when ED visits are included. Although non-Hispanic blacks had a lower likelihood of hospital death, related to their higher number of outpatient ED visits, the overall Illinois opioid 


\section{Figure 2}

Monthly trends in visits by zip code tabulation area percent poverty households, 214 Illinois hospitals, 1/2016-6/2019.

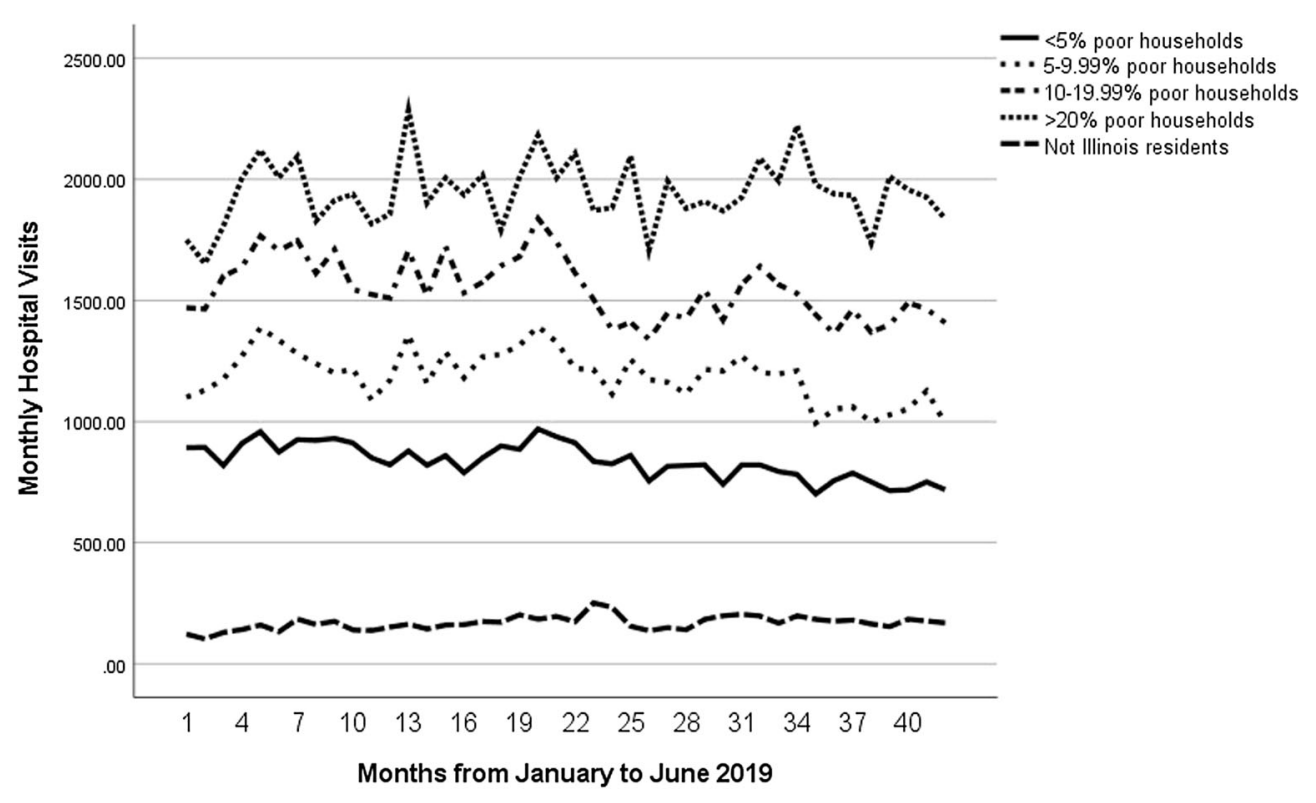

death rate, which includes deaths in the community, is twice as high for non-Hispanic blacks than non-Hispanic whites. ${ }^{1}$

The fact that non-Hispanic black individuals were less likely to die in the hospital than nonHispanic whites likely reflects this fact. Large numbers of fentanyl-related rapid overdoses result in community deaths where EMS are more likely to find an individual who has already expired, as opposed to prescription opioid overdoses which are more common in suburban areas among nonHispanic whites. ${ }^{8}$ An additional factor is likely differential access to primary and hospital care, reflected by visits related to overdose rather than use, abuse, and dependence. As can be seen in Table 1, non-Hispanic whites accounted for $45.5 \%$ of all hospital visits but $50.5 \%$ of all overdose coded visits while non-Hispanic blacks accounted for $37.2 \%$ of all visits but only $31.6 \%$ of overdose visits.

\section{Implications for the National Debate on Causes of the Opioid Crisis}

The Cook County fentanyl deaths study illustrates a broader debate about the nature of the opioid epidemic nationally. On the one hand, the national narrative about opioid addiction has focused on "deaths of despair," most eloquently described in the recent work of Case and Deaton. ${ }^{9}$ Their 2015 study demonstrated that from 1999 to 2013, midlife mortality rates climbed for non-Hispanic whites. The mortality increase was greatest among whites without college education and was driven by mental health-related deaths including suicide, liver disease, and drug and alcohol poisonings, including non-opioid overdose deaths. ${ }^{10,11}$ This explanation focuses on despair among lower-income, rural, and small town whites whose social position has eroded in the wake of deindustrialization and emphasizes cultural aspects and feelings of individual failure, family dissolution, shame, and chronic pain. ${ }^{12,13}$ In this view, the increase in addiction among 
Incidence rate ratios (IRR) for risk factors for opioid-related hospital death or hospital inpatient admission 214 Illinois Hospitals, 1/2016-6/2019.

\begin{tabular}{|c|c|c|}
\hline & $\begin{array}{c}\text { Deaths, IRR } \\
(95 \% \mathrm{CI})\end{array}$ & $\begin{array}{l}\text { Hospital admission, } \\
\text { IIR }(95 \% \mathrm{CI})\end{array}$ \\
\hline \multicolumn{3}{|l|}{ Year } \\
\hline 2016 & Reference & Reference \\
\hline 2017 & $0.95(0.84-1.09)$ & $0.96(0.94-0.99)$ \\
\hline 2018 & $0.98(0.84-1.14)$ & $0.94(0.90-0.97)$ \\
\hline 2019 & $0.95(0.80-1.15)$ & $0.92(0.87-0.97)$ \\
\hline \multicolumn{3}{|l|}{ Sex } \\
\hline Male & $0.92(0.83-1.15)$ & $0.96(0.94-0.98)$ \\
\hline \multicolumn{3}{|l|}{ Race/ethnicity } \\
\hline Non-Hispanic White & Reference & Reference \\
\hline Non-Hispanic Black & $0.78(0.62-0.98)$ & $1.02(0.98-1.08)$ \\
\hline Hispanic & $0.75(0.55-1.13)$ & $1.02(0.94-1.11)$ \\
\hline Asian & $0.64(0.21-1.91)$ & $1.10(1.06-1.18)$ \\
\hline Unknown or Other & $1.11(0.67-1.80)$ & $1.11(0.95-1.29)$ \\
\hline \multicolumn{3}{|l|}{ Age group } \\
\hline $0-19$ & $0.58(0.32-1.04)$ & $1.11(1.03-1.20)$ \\
\hline $20-44$ & Reference & Reference \\
\hline $45-64$ & $1.80(1.59-2.04)$ & $1.07(1.03-1.12)$ \\
\hline $65+$ & $3.31(2.41-4.53)$ & $1.13(1.07-1.19)$ \\
\hline \multicolumn{3}{|l|}{ Insurance } \\
\hline Private & Reference & Reference \\
\hline Medicaid & $0.91(0.77-1.08)$ & $0.92(0.86-0.99)$ \\
\hline Medicare Age 65 & $0.98(0.67-1.41)$ & $1.10(1.02-1.18)$ \\
\hline Medicare disability & $0.93(0.73-1.15)$ & $1.10(1.03-1.16)($ \\
\hline Uninsured & $0.84(0.67-1.04)$ & $0.51(0.46-0.55)$ \\
\hline Other/unknown & $1.43(0.90-2.28)$ & $0.94(0.80-1.11)$ \\
\hline \multicolumn{3}{|l|}{ Illinois county area } \\
\hline Cook & Reference & Reference \\
\hline DuPage, Kane, Will, Lake, or McHenry County & $1.09(0.85-1.39)$ & $0.95(0.90-1.01)$ \\
\hline Downstate & $1.11(0.85-1.36)$ & $0.94(0.86-1.02)$ \\
\hline Rural/small metro county & $0.94(0.72-1.21)-$ & $0.92(0.83-1.01)$ \\
\hline \multicolumn{3}{|l|}{ Day of encounter } \\
\hline Weekend & $1.17(1.03-1.33)$ & $0.95(0.93-0.96)$ \\
\hline \multicolumn{3}{|l|}{ ICD-10 coded category of opioid use } \\
\hline Opioid overdose & $2.43(1.87-3.16)$ & $0.56(0.46-0.66)$ \\
\hline Opioid abuse & $1.42(1.11-1.81)$ & $0.94(0.84-1.06)$ \\
\hline Opioid dependence & $0.63(0.48-0.82)$ & $1.46(1.30-1.64)$ \\
\hline Opioid use & Reference & Reference \\
\hline \multicolumn{3}{|c|}{ Zip code tabulation area poverty percent of poor households } \\
\hline$<5 \%$ of ZCTA & $1.14(0.90-1.45)$ & $1.00(0.95-1.05)$ \\
\hline $5-9.99 \%$ of ZCTA & $1.12(0.89-1.41)$ & $0.99(0.95-1.04)$ \\
\hline $10-19.99 \%$ of ZCTA & $1.06(0.87-1.30)$ & $0.99(0.95-1.03)$ \\
\hline$>20 \%$ of ZCTA & Reference & Reference \\
\hline Not Illinois resident & $1.12(0.78-1.61)$ & $1.07(0.97-1.20)$ \\
\hline
\end{tabular}


rural and small town white populations was a sign of hopelessness and lowered expectations for social mobility, while in contrast, minority communities, while also historically economically depressed, have experienced greater social solidarity and an increase in hopefulness about the future.

Alternative analyses emphasize local, place-specific "supply" factors as more important drivers of the opioid epidemic than "demand" factors. ${ }^{14}$ In this view, access to drugs has been the key driver of the epidemic, with addiction rates high in some states that had far less economic decline than Appalachia and the Rustbelt. ${ }^{15}$ The modern opioid epidemic grew out of aggressive opioid marketing to mainly white populations through about 2010, later fueled by the substitution of cheaper heroin from Mexican cartels in the Eastern United States after closure of pill mills and increased prescription surveillance. ${ }^{16}$ The limited effect of (recently declining) opioid prescriptions was illustrated by the fact that over $30 \%$ of Illinois opioid overdose decedents in 2016 had no prescriptions in the 6 years prior to their death. ${ }^{17}$ This reflects a rapid shift to overdose deaths concentrated among disproportionately Millennial, male, and minority populations. Ruhm finds that while counties experiencing economic decline from 1999 to 2015 had higher increases in "deaths of despair," this association was confounded by the proportion of female, non-white, and foreign born residents, along with other socioeconomic factors distinguishing rural areas, making the association of opioid deaths with economic decline largely illusory. ${ }^{18}$ As Geronimus and others have argued, the opioid epidemic represents a spike in what was already deteriorating life expectancy for poor and working class Americans in the wake of rapidly growing income inequality. ${ }^{19}$

\section{State Health Policy}

The Heroin Crisis Act of 2015 was a bipartisan Illinois state law that expanded access to opioid addiction treatment and overdose prevention, ${ }^{20}$ increasing physician buprenorphine training, and expanding access to naloxone to decrease the likelihood of patients dying prior to even having a chance of reaching the ED. ${ }^{21,22}$ The Illinois Department of Human Services Division of Alcoholism and Substance Abuse was given support from the federal government in the form of a State Targeted Response to the Opioid Crisis grant in 2017. The Illinois Opioid Action Plan of 2017 was created to reduce opioid deaths in Illinois by $33 \%$ in 3 years. The plan outlines a total of nine strategies that the State would focus on, including increasing access to care to those with opioid use disorder, dissuading healthcare professionals from high-risk prescribing, and supporting data collection, analysis, and sharing. ${ }^{23}$ In Chicago, there has been a renewed emphasis on "warm handoffs" to community-based behavioral health, including a shift to integrate behavioral health within primary care services offered through the Cook County public hospital system. One focus has been increased access to medical-assisted treatment (MAT) for opioid addiction, which includes taking an opioid agonist medication daily to subdue the body's physiological and chemical cravings for opioids without the risk for overdose and death.

The effectiveness of these state and local interventions will be tested by the many clinical, logistical, staffing, and bureaucratic obstacles that have plagued well-intentioned programs in other states. ${ }^{24,25}$ Far greater resources will be needed for the state to address the full range of evidencebased screening, prevention, and treatment recommendations. ${ }^{26-28}$ These recommendations include resources for more comprehensive medical examiner and coroner reports, linking individuals who survive non-fatal overdoses to treatment; halting or limiting indications for long term, non-cancerrelated opioid prescriptions for chronic pain; increasing insurance coverage for nonpharmacological pain management; and making buprenorphine or methadone treatment much more easily available through primary care, including at federally qualified health centers. Perhaps most importantly are proven harm reduction strategies, such as access to safe syringes, fentanyl test 
strips, and take home naloxone, and perhaps most effective, safe consumption sites. ${ }^{29-31}$ Following successful life-saving international examples, US cities may soon also provide supervised safe consumption facilities. ${ }^{32}$ Crucial for the success of all responses to the epidemic, and especially for reducing fentanyl mortality, is decriminalization of illicit opioids, including pre-trial or post-arrest diversion programs. Decriminalization could reduce the enormous costs of policing, criminal prosecution, incarceration, and drug trade violence and, by reducing stigma, allow those suffering from substance use to seek treatment more freely. Finally, treatment must go beyond "detox" programs to recovery programs based on integrated mental healthcare, MAT, post-discharge patient navigation and "wrap-around" social services related to housing, employment, and childcare. $^{33}$

\section{Implications for Hospital Care}

People with substance use disorder present to hospitals with major medical and mental health illnesses, high-risk COVID-19 complications as well as drug-related injuries, exacerbated by homelessness, incarceration, and trauma. Uncertainty about drug supply and the corresponding increased risks of withdrawal will likely increase high-risk behavior. As eloquently described in a recent article by Englander et al., the loss of health insurance, jobs, and social isolation of the COVID-19 pandemic will disproportionately affect people in recovery as well. ${ }^{34}$ Englander et al. prioritize hospitals' addiction recovery resources, including the ability to provide digital connectivity and software to keep track of appointments and alert case workers when a patient is becomes a "no show."

Hospitals will need significant financial incentives to link patients to more comprehensive substance use care. ${ }^{35}$ One example from the pre-COVID period was programs using state Section 1115 Medicaid waivers to increase reimbursement for short-term residential and inpatient treatment, co-located primary care counseling and MAT, "carved in" behavioral health for Medicaid managed care entities, and reimbursement for peer recovery supports. Evaluations of these programs show promise in retaining patients in treatment and reducing hospital use for opioid use $^{36,37}$ and software to keep track of appointments and alert case workers when a patient is marked as "no show." There is also promising evidence of the effectiveness of initiating buprenorphine treatment in the ED or inpatient setting as an alternative to traditional referral to treatment. $^{22}$

\section{Limitations and Conclusion}

The most important limitation of this study is the lack of patient identifiers, making it impossible to link visits to individual patients. This makes it impossible to trace patterns of repeat ED visits or hospitalizations for the same individuals or to link hospital use to death certificate and coroner records, including for patients who died in the community. Future data linkages, including to outpatient care, prescriptions, drug treatment, and provision of social services will be essential for the health system to effectively address the opioid epidemic. While building such a data infrastructure will be expensive and challenging, but as this study documents, the costs could eventually be offset by enormous savings in acute hospital care for opioid use.

\section{Acknowledgments}

The authors would like to thank Elizabeth Salisbury-Afshar MD MPH for her health policy guidance. 


\title{
Compliance with Ethical Standards
}

\author{
Conflict of Interest None of the authors has any conflicts of interest.
}

\section{References}

1. Illinois Department of Public Health. Opioid data dashboard. 2019. http://idph.illinois.gov/opioiddatadashboard/. Accessed 5 June 2020.

2. Haley DF, Saitz R. The Opioid Epidemic During the COVID-19 Pandemic. Journal of the American Medical Association. 2020.

3. Centers for Disease Control and Prevention. Opioid overdose: overdose data to action. 2019. https://www.cdc.gov/drugoverdose/od2a/ index.html. Accessed 6 Jan 2021.

4. Krawczyk N, Eisenberg M, Schneider KE, et al. Predictors of Overdose Death Among High-Risk Emergency Department Patients With Substance-Related Encounters: A Data Linkage Cohort Study. Annals of Emergency Medicine 2020;75(1):1-12.

5. Kilaru A, Xiong A, Lowenstein M, et al. Incidence of Treatment for Opioid Use Disorder Following Nonfatal Overdose in Commercially Insured Patients. Journal of the American Medical Association Network Open. 2020;3(5).

6. Centers for Disease Control and Prevention. Opioid overdose: opioid data analysis and resources. 2019. https://www.dcd.gov/ drugoverdose/data/analysis.html. Accessed 25 Jan 2021.

7. Abbasi AB, Salisbury-Afshar E, Berberet CE, et al. Opioid Prescribing Patterns Before Fatal Opioid Overdose. American Journal of Preventive Medicine 2020;58(2):250-253.

8. Nesoff ED, Branas CC, Martins SS. The Geographic Distribution of Fentanyl-Involved Overdose Deaths in Cook County, Illinois. American Journal of Public Health. 2020;110(1):98-105.

9. Case A, Deaton A. Deaths of despair and the future of capitalism. Princeton: Princeton University Press; 2020.

10. Case A, Deaton A. Rising morbidity and mortality in midlife among white non-Hispanic Americans in the 21st century. Proceedings of the National Academy of Science U S A. 2015;112(49):15078-15083.

11. Ruhm CJ. Nonopioid overdose death rates rose almost as fast as those involving opioids, 1999-2016. Health Affairs (Millwood). 2019;38(7):1216-1224.

12. Quinones S. Dreamland: the true tale of America's opiate epidemic. New York: Bloomsbury Press; 2016.

13. Vance JD. Hillbilly elegy: a memoir of a family and culture in crisis. New York: HaperCollins Publishers; 2016.

14. Finkelstein A, Gentzkow MA, Williams H. What drives prescription opioid abuse?: evidence from migration. Stanford: SIEPR, Stanford Institute for Economic Policy Research; 2018.

15. Ruhm CJ. Geographic variation in opioid and heroin involved drug poisoning mortality rates. American Journal of Preventive Medicine 2017;53(6):745-753.

16. Lin D, Liu S, Ruhm CJ. Opioid deaths and local healthcare intensity: a longitudinal analysis of the U.S. population, $2003-2014$. American Journal of Preventive Medicine. 2020;58(1):50-58.

17. Abbasi AB, Salisbury-Afshar E, Jovanov D, et al. Health care utilization of opioid overdose decedents with no opioid analgesic prescription history. Journal of Urban Health. 2019;96(1):38-48.

18. Ruhm CJ. Drivers of the fatal drug epidemic. Journal of Health Economics 2019;64:25-42.

19. Muennig PA, Reynolds M, Fink DS, et al. America's declining well-being, health, and life expectancy: not just a white problem. American Journal of Public Health. 2018;108(12):1626-1631.

20. Illinois Department of Human Services. Governor Pritzker signs executive order to fight opioid crisis and reduce racial disparities. 2020. https://www.dhs.state.il.us/OneNetLibrary/27896/documents/2020SmartAlerts/Smart_Alert_Volume_XIII,_Issue_XX__Executive_Order_Regarding_Opioid_Crisis.pdf. Accessed 6 Jan 2021.

21. Abouk R, Pacula RL, Powell D. Association between state laws facilitating pharmacy distribution of naloxone and risk of fatal overdose. Journal of the American Medical Association Internal Medicine 2019;179(6):805-811.

22. D'Onofrio G, O'Connor PG, Pantalon MV, et al. Emergency department-initiated buprenorphine/naloxone treatment for opioid dependence: a randomized clinical trial. Journal of the American Medical Association. 2015;313(16):1636-1644.

23. Illinois Department of Public Health. Opioids: Illinois plan. 2019. https://www.dph.illinois.gov/opioids/ilplan. Accessed 25 Jan 2021.

24. Strach P, Zuber K, Perez-Chiques E. Why policies fail: the illusion of services in the opioid epidemic. Journal of Health Policy Politics and the Law. 2020;45(2):341-364.

25. Kim HS, Samuels EA. Overcoming barriers to prescribing buprenorphine in the emergency department. Journal of the American Medical Association Network Open. 2020;3(5):e204996.

26. Kolodny A, Frieden TR. Ten steps the federal government should take now to reverse the opioid addiction epidemic. Journal of the American Medical Association. 2017;318(16):1537-1538.

27. Saloner B, McGinty EE, Beletsky L, et al. A public health strategy for the opioid crisis. Public Health Reports. 2018;133(1 suppl):24S34S. https://doi.org/10.1177/0033354918793627.

28. Compton WM, Volkow ND, Throckmorton DC, et al. Expanded access to opioid overdose intervention: research, practice, and policy needs. Annals of Internal Medicine 2013;158(1):65-66.

29. Peiper NC, Clarke SD, Vincent LB, et al. Fentanyl test strips as an opioid overdose prevention strategy: Findings from a syringe services program in the Southeastern United States. International Journal of Drug Policy. 2019;63:122-128. 
30. Eswaran V, Allen KC, Cruz DS, et al. Development of a take-home naloxone program at an urban academic emergency department. Journal of the American Pharmacists Association (2003). 202060(6):e324-e331. https://doi.org/10.1016/j.japh.2020.06.017.

31. Kral AH, Lambdin BH, Wenger LD, et al. Evaluation of an Unsanctioned Safe Consumption Site in the United States. New England Journal of Medicine 2020;383(6):589-590.

32. Potier C, Laprevote V, Cottencin O, et al. Supervised injection services: what has been demonstrated? A systematic literature review. Drug and Alcohol Dependence. 2014;145:48-68.

33. Wakeman SE, Rigotti NA, Herman GE, et al. The effectiveness of post-discharge navigation added to an inpatient addiction consultation for patients with substance use disorder; a randomized controlled trial. Substance Abuse. 2020:1-8. https://doi.org/10.1080/ 08897077.2020.1809608.

34. Englander H, Salisbury-Afshar E, Gregg J, et al. Converging Crises: Caring for Hospitalized Adults with Substance Use Disporder in the Time of Covid-19. Hospital Medicine. 2020;15(10):628-630.

35. Kilaru AS, Perrone J, Kelley D, et al. Participation in a Hospital Incentive Program for Follow-up Treatment for Opioid Use Disorder. Journal of the American Medical Association Network Open. 2020;3(1):e1918511.

36. Barnes AJ, Cunningham PJ, Saxe-Walker L, et al. Hospital Use Declines After Implementation Of Virginia Medicaid's Addiction And Recovery Treatment Services. Health Affairs (Millwood). 2020;39(2):238-246.

37. Hadland SE, Bagley SM, Rodean J, et al. Receipt of Timely Addiction Treatment and Association of Early Medication Treatment With Retention in Care Among Youths With Opioid Use Disorder. Journal of the American Medical Association Pediatrics. 2018;172(11):1029-1037.

Publisher's Note Springer Nature remains neutral with regard to jurisdictional claims in published maps and institutional affiliations. 